\title{
1. Metaphors and judicial frame: why legal imagination (also) matters in the protection of fundamental rights in the digital age
}

\section{Oreste Pollicino}

\section{INTRODUCTION: THE THEORETICAL BACKGROUND}

The shift from a concept of the metaphor as an exclusively linguistic phenomenon to a concept that involves a cognitive process and a conceptual framework occurred with the publication of the volume Metaphors We Live By by Lakoff and Johnson in $1980 .{ }^{1}$ This study marked a genuine paradigm shift, from which research was launched into the role and potential of the metaphor in a wide variety of fields (from politics to religion, from economics to the law, and so on). Two central theses of modern cognitive linguistics were endorsed by the subsequent studies: the idea that language is not autonomous from other human cognitive activities (such as perceiving, reasoning, and so on) and the conviction that there is a close link between meanings and concepts.

The fundamental theoretical assumption underlying research into the conceptual paradigm is therefore that the metaphor is more a phenomenon of thinking than of language. ${ }^{2}$ According to this view, every metaphor has a 'source domain', a 'target domain' and 'source-to-target mapping'. ${ }^{3}$ The metaphorical processes that are developed through shifts from one domain to the other are considered to correspond to the cognitive structures that condition human understanding.

\footnotetext{
1 G Lakoff and M Johnson, Metaphors We Live By (University of Chicago Press 1980).

2 A Contini, 'La forza cognitiva della metafora: convergenze e divergenze nel dibattito novecentesco' (2016) 6(1) I castelli di Yale online cit 30.

3 G Lakoff, Women, Fire, and Dangerous Things: What Categories Reveal about the Mind (University of Chicago Press 1987) 276.
} 
Based on the conceptual and cognitive paradigm of the metaphor, it is also possible to infer a paradigm that is useful for studying some interesting issues arising in relation to the judicial protection of fundamental rights with respect to the internet to inform the judicial frame.

Within the specific context of judicial argumentation, a judicial frame is the expressive structure and, more broadly, the reference context for the reasoning set out in the judgment. As this chapter will demonstrate, depending upon the particular judicial frame chosen by a judge who considers how a right should be protected within the 'world of bits', different balances will be struck, and different solutions will be found - in some cases very different - even in cases that are essentially similar or identical. Using the conceptual and cognitive paradigm of the metaphor, the idea is to shift the notion of frame from a cognitive study to the theory of interpretation and argumentation.

There is at least one reason to apply the notion of frame to the protection of fundamental rights in the digital age. On the one hand, metaphorical constructs within judicial argumentation operate as 'vehicles' that can lead to different conceptual areas and value contexts. Behind every metaphor there is a world of logically interrelated concepts. The preference for one conceptual world over another is the result of a precise axiological choice by the decision maker. Analysis of judicial frames of reference and the conceptual source and target domains of metaphorical shifts not only makes it possible to reconstruct with precision the argumentative steps taken within the judicial decision making processes, but also allows for greater precision when measuring the consistency (or lack thereof) of the decisions reached compared to the positions previously stated by the same decision making bodies, or by any other body addressing identical or similar questions. Metaphorical conceptualisation is necessary in order to resolve judicial disputes concerning the online realm, which is a particularly interesting field of inquiry. Thus, the study of the manner in which metaphorical conceptualisation is engaged, in establishing the judicial frame, offers valuable indications when addressing the current tendencies followed by the highest courts in contemporary democracies.

\section{JUDICIAL BALANCING AND JUDICIAL FRAME IN ACTION}

Against this background, one should not underestimate the role of the courts in formulating the current global agenda. Some researchers even speak of the 'judicialisation' of legal regimes; that is, the feedback effect of judicial law-making, where States delegate significant 'political property rights' to 
courts. ${ }^{4}$ This effect is amplified by 'judicial globalisation', which is a 'process of judicial interaction across, above, and below borders, exchanging ideas and cooperating in cases involving national as much as international law'.5

Barak sees judicial balancing as 'a metaphor, which assumes the shape of a scale', ${ }^{6}$ on one side of which are the goals to be achieved, while on the other side are the limitations on rights. Whenever courts attempt to solve the 'balancing equation', they have to decide between the marginal benefit to the public good and the marginal limitation on human rights. The act of balancing may be either 'definitional', where courts apply specific methodologies to arrive at outcomes with a degree of predictability, or 'procedural', where such an activity can be sliced into distinct logical steps, which tend to transform the underlying legal reasoning from a prudential to a procedural kind of judgement activity. ${ }^{7}$ According to Durante:

a fair and ethical balance between competing interests is to be based, as far as possible, on the reduction of informational asymmetries or at least on sufficient and satisfactory explanations for such asymmetries. Individual rights can be partially sacrificed only on the basis of information and explanations, which provide individuals, through the judicial activity of the Courts, with a clear and reasonable understanding of what this sacrifice is for. ${ }^{8}$

With regard to balancing in the digital era, 'the demands of a democratic society and its obligations towards protecting individual rights must be balanced against the need and appetite for electronic commerce and information

4 A Stone Sweet and TL Brunell, 'Trustee Courts and the Judicialization of International Regimes' (2013) 1 Journal of Law and Courts 62.

5 See A Slaughter, 'Judicial Globalization' (2000) 40 Virginia Journal of International Law 1104. She distinguishes five different categories of judicial interaction: relations between national courts and the European Court of Justice in the European Union; interactions between the European Court of Human Rights and national courts; the emergence of 'judicial comity' in transnational litigation; constitutional cross-fertilisation; and face-to-face meetings among judges around the world. The contexts are very different, involving both 'vertical' relations between national and international tribunals and 'horizontal' relations across national borders. According to Slaughter, the factors driving these forms of interaction also vary widely, including a structural provision in an international treaty, the globalisation of commerce and the need for judicial training in many fledgling democracies.

6 A Barak, 'Proportionality and Principled Balancing' (2010) 4(1) Law and Ethics of Human Rights 7, with further references.

7 M Durante, 'Dealing with Legal Conflicts in the Information Society. An Informational Understanding of Balancing Competing Interests' (2013) 26(4) Philosophy \& Technology 446-47.

8 See Durante (n 7) 455. 
technology'. ${ }^{9}$ The speed of cyberspace development so far provides evidence that 'the technical ability leads the policy component, which in turn is ahead of the legal and wider political framework'. ${ }^{10}$ This predicament gives momentum to the various searches for solutions in areas that are lagging behind the technical developments. As Sajo points out, the 'translation of a technology and its consequences into the legal frame is not automatic'. ${ }^{11}$ This is where courts play an important role, through the judicial process of translating something new into the language of past legal models ${ }^{12}$ by means of the judicial framing technique. In other words, whenever judges are confronted with issues requiring a certain amount of technical expertise not related specifically to the legal domain, judicial decision making processes are influenced by the contextualisation of a given issue, arising from real life, into a legal frame. ${ }^{13}$ This framing activity shapes the legal argumentation, and is characterised by the recurrence of words, lemmas or rhetoric formulas. Examples of the judicial framing approach include the use of the term 'piracy' in copyright infringement disputes related to the peer-to-peer exchange of data or resorting to the word 'privacy' in data protection disputes. ${ }^{14}$

A second layer of complexity is the nature of the Internet itself. It is borderless on the one hand and multi-jurisdictional ${ }^{15}$ on the other. The globalisation of the information society 'progressively erodes the traditional distinction between national and supranational spaces'. ${ }^{16}$

9 A Rengel, 'Privacy in International Law Privacy as an International Human Right and the Right to Obscurity in Cyberspace' (2014) 2(2) Groningen Journal of International Law 42.

10 A Klimburg, The Darkening Web (Penguin Random House 2017) 6.

11 A Sajó and C Ryan, 'Judicial Reasoning and New Technologies: Framing, Newness, Fundamental Rights and the Internet' in O Pollicino and G Romeo (eds), The Internet and Constitutional Law: The Protection of Fundamental Rights and Constitutional Adjudication in Europe (Routledge 2016) 7.

12 ibid 8.

13 C Riley, 'The Rite of Rhetoric: Cognitive Framing in Technology Law' (2009) 9(3) Nevada Law Journal 495-544.

14 O Pollicino and G Romeo (2016) 'Concluding Remarks: Internet Law, Protection of Fundamental Rights and the Role of Constitutional Adjudication' in O Pollicino and G Romeo (eds), The Internet and Constitutional Law: The Protection of Fundamental Rights and Constitutional Adjudication in Europe (Routledge 2016) 237-8.

15 See, for a general discussion, O Pollicino and M Bassini, 'Free Speech, Defamation and the Limits to Freedom of Expression in the EU: A Comparative Analysis' in A Savin and J Trzaskowski (eds), Research Handbook on EU Internet Law, 1st edn (Edward Elgar Publishing 2014) 508-42; B Maier, 'How Has the Law Attempted to Tackle the Borderless Nature of the Internet?' (2010) 18(2) International Journal of Law and Information Technology 142-75.

16 See Durante (n 7) 437-57, with further references. The approaches on the different sides of the Atlantic differ. While the US Supreme Court does not appear to be 
A third layer of complexity relates to the fact that there are two different approaches to State cyber power: a liberal 'free internet' approach, in which the proponents see the State as a mild regulator of the online domain, and a restrictive 'national cyber sovereignty' approach that accentuates the authority of States to control the information that flows within their borders strictly. For example, the Russian authorities, together with like-minded States such as China and Iran, being proponents of the second approach, have repeatedly emphasised the point that information in all its forms is a weapon, which is most often employed by terrorists. ${ }^{17}$ Essentially, the approach of these States maintains and highlights the notion that information on the Web should be managed rather than free-flowing. In the international arena, the views of the 'managed flow' proponent States were codified in the International Code of Conduct for Information Security, ${ }^{18}$ which was submitted for consideration to the UN General Assembly in January 2015 by the founding Member States of the Shanghai Cooperation Organisation - China, Russia, and the stan countries. ${ }^{19}$ The burden of keeping track of the often conflicting wishes of legislators in the different nation States falls heavily on the shoulders of courts. Nowadays, courts occupy a 'privileged position that enables them to identify the risk of potential collisions that may encroach upon the effective protection of fundamental rights between interconnected legal systems' ${ }^{20}$

Naturally, a question arises as to the qualification of the judges to tackle IT-related issues and to go deeply into technicalities. Sajo notes that the new technology may generate decisional uncertainty, owing to the fact that the

overly concerned with the fact that, by definition, the trans-national nature of the internet can have a substantial effect on the efficiency and even feasibility of domestic regulations striking a national balance between contrasting fundamental rights, the same concern is clear in the relevant case law of the European courts. Also see O Pollicino, 'The European Judicial Dialogue and the Protection of Fundamental Rights in the New Digital Environment' in S Morando-Foadi (ed), The Case of Freedom of Speech, Fundamental Rights in the EU: A Matter for two Courts (Hart 2015) 112.

17 See Klimburg (n 10) 105-10.

18 Letter dated 9 January 2015 from the Permanent Representatives of China, Kazakhstan, Kyrgyzstan, the Russian Federation, Tajikistan and Uzbekistan to the United Nations addressed to the Secretary-General. Available at: [ccdcoe.org/sites/ default/files/documents/UN-150113-CodeOfConduct.pdf] (accessed 17 December 2017).

19 This draft document was criticised for being 'a fundamental challenge to the flourishing of global thought and discourse through the Internet, as well as to the established framework of international human rights law': see S McKune, 'An Analysis of the International Code of Conduct for Information Security' (2015) The Citizen Lab. Available at: [citizenlab.ca/2015/09/international-code-of-conduct/] (accessed 4 January 2018).

20 See Pollicino (n 16) 94. 
applicable constitutional rights and norms are often deliberately vague; the meaning and implications of a new technology therefore may not be evident to the judge. ${ }^{21}$ Should the society or the professional community of judges be in search of multi-disciplinary court judges? Could a professional judicial dialogue between courts of different jurisdictions help to foster an exchange of experiences, avoid fragmentation and ensure coherence between legal systems, as well as develop a single vision for judicial balancing online ${ }^{22}$ At the European level, this dialogue was recently undertaken in the SABAMv Scarlet line of cases concerning the obligations of internet service providers. ${ }^{23}$ The dialogue was undertaken in two directions: horizontally - between the Court of Justice of the European Union and the European Court of Human Rights - and vertically - between the supranational and national courts. ${ }^{24}$ However, with regard to a potential wider judicial dialogue between courts on different sides of the Atlantic Ocean, the author has a more pessimistic outlook. The difference between the constitutional visions of fundamental rights in Europe and the US may be difficult to reconcile. ${ }^{25}$

In order to attempt to provide examples of the arguments set out above and thus to tease out the connection between metaphorical language, judicial frames and the protection of fundamental rights within the digital realm, it may be useful to compare the two following quotations.

The Court notes that Article 1 of Law no. 47 of 1948 limits itself to an explicit definition of the concept of the press in its technical sense of reproduction through typographical means or otherwise using mechanical or physical-chemical means. However, the term "press" also has a figurative meaning and, in that sense, refers to newspapers, which are an instrument of choice for obtaining information, and were so above all at the time when the Constitution and Law no. 47 of 1948 came into force, that is when other forms of mass media, in particular television and online information sites, were not in operation. This concept of press in a figurative sense defines the editorial product that features both the ontological prerequisite (structure) and the teleological prerequisite (purposes of publication) for a newspaper.

$21 \quad$ See Sajó and Ryan (n 11) 8.

22 See, for an overview on the concept of judicial dialogue, O Pollicino and $\mathrm{G}$ Martinico, The Interaction between Europe's Legal Systems: Judicial Dialogue and the Creation of Supranational Laws (Edward Elgar Publishing 2012).

23 Case C-70/10 Scarlet Extended SA v SABAM [2011] ECR I-11959 and Case C-360/10 SABAMv Netlog NV [2012] ECR-0000.

24 European Judicial Cooperation in the Fundamental Rights Practice of National Courts. European University Institute. Available at: [www.eui.eu/Projects/ CentreForJudicialCooperation/Documents/JUDCOOPdeliverables/FinalHand bookUseofJudicialInteractionTechniquesinthefieldofEFRs.pdf] (accessed 3 July 2018).

25 See Pollicino (n 16) 112. 
Now you can see the meaning of my title cyberspace and the Law of the Horse. When asked to talk about Property in Cyberspace, my reaction was, 'Isn't this just the law of the horse?' ... This leads directly to my principal conclusion: Develop around law of intellectual property, then just apply it to computer networks.

The two quotes apparently have very little in common. The first comes from an Italian judgment (the Joint Divisions of the Court of Cassation) ${ }^{26}$ from January 2015 on a specific issue relating to the application to the internet (and in particular to remote and electronic magazines) or rules originally intended for the printed press. The second comes from a paper penned by another judge, Frank Easterbrook, ${ }^{27}$ in his 'academic capacity' for a conference held in Chicago dedicated to the nascent cyberspace. In this paper, in the early days of the internet in 1995, the judge poses the question, ironically, whether it would make any sense to speak of the 'law of horses' when it would be sufficient to refer to the more general 'law of animals'; he thus proposes that there is no need to adopt any new legislation for the digital world, but quite simply, the traditional legal rules could be applied from the real world to the new technological realm, according to a common sense approach.

In actual fact, however, despite their differences, the two quotes highlight the very same dilemma with which both practitioners and lawmakers are confronted when they are required to 'transfer' certain categories, both legal and non-legal, from the realm of the analogue to the digital world. A choice must be made between a shift and a transposition sic et simpliciter of traditional categories to the new technological context, and the need to rethink and reshape those categories due to the need to adapt them to (or to change in the light of) a completely different technological scenario.

The choices made in the two passages cited above appear to suggest two diametrically opposed choices. In the first, the Joint Divisions of the Court of Cassation propose a rethinking 'in a figurative sense' of something (the concept of the press) that had been previously defined in a technical sense, to open that concept to the technological evolution and in particular the impact of the internet.

In the second case, on the other hand, the words of Easterbrook reveal a value frame of resistance to the emerging technology, which is illustrated by the call for a mere shift in the application of the traditional legal toolkit to the digital world. However, in both cases, the interpreting bodies, and in particular the courts, cannot refrain from exercising - in the words of James Boyd

Cass pen, SS UU, 17 July 2015 (ud 29 January 2015), n 31022.

27 FH Easterbrook, 'Cyberspace and the Law of the Horse' (1996) University of Chicago Legal Forum 207. 
White ${ }^{28}$ - their 'legal imagination', whether the proposal is to reconsider the existing rules (which may even result in their alteration), due to changes in the technological circumstances, or whether to shift those rules from the material level to the intangible level.

It is clear that, whatever solution is adopted, the courts in general, and the constitutional (or supreme) courts in particular, appear to play a very delicate role as they are required to choose - in the words of Sunstein ${ }^{29}$ - between 'constitutional translation and constitutional caution'. The courts must decide whether to translate the values upholding the original constitutional principles according to a technologically informed interpretation of the relevant parameters to enable them to be extended to cover the new requirements emerging as a result of technological evolution, or whether a preferable approach would be one marked by self-restraint, leaving this task to the politicians. In other words, it is necessary to understand whether the more appropriate approach in these cases is one of judicial deference or of judicial activism, also considering the question of not inconsiderable importance of the relationship between politics and the courts within the context of digital law.

The concept of frame proposed by Lakoff appears to be useful in this dilemma, as it describes a constitutive use of the metaphor, which acts as the focal point for a context that operates as its indispensable framework. The usefulness of the concept of frame for these present purposes is evident. In transferring the concept from the domain of theory of language and cognitive sciences to that of the theory of interpretation and argumentation, and hence identifying the judicial frame as a sub-class of frame, ${ }^{30}$ it is possible to establish which basic value choices can act as a frame for the use of a specific metaphor by the courts and act as the basis for a particular judicial balancing operation.

Apparently - although the scenario is much more complex - there would appear to be only two argumentative options: either to re-contextualise the relevant parameters, creating new frames in the light of the technological environment, or to adopt a stance of judicial deference towards the legislature. The latter is a solution supported, for example, by Lessig: 'My sense is that, knowing nothing, or at least not very much, terrified by the threats of which they don't know, these judges will defer to democratic authority.' 31

There is however still a problem: the courts must rule on the case that is presented before them and they do not have much choice regarding this

\footnotetext{
28 JB White, The Legal Imagination, 2nd edn (University of Chicago Press 1985).

29 CR Sunstein, 'Constitutional Caution' (1996) 1 University of Chicago Legal Forum Article 11.

$30 \quad$ See Sajó and Ryan (n 11) 3 ss.

31 L Lessig, 'Reading the Constitution in Cyberspace' (1996) 45(3) Emory Law Journal 874.
} 
matter. Justice Kennedy's dissenting opinion in Denver Area Educational Telecommunications Consortium ${ }^{32}$ on the regulation of cable television, which was decided in 1996 by the US Supreme Court, is emblematic in this regard. In his opinion, he stated, in relation to the technological factor (which was new at the time), that 'we don't know yet, but here's the best we can'. Kennedy persuaded the other justices, arguing that 'doubt and caution may be reasons for the Supreme Court not to take a case, but once taken, it is hard to accept the attitude of the Court to not decide. This is why metaphors and analogies to other areas of our First Amendment case law become a responsibility, rather than the luxury the plurality considers them to be.'

In other words, a decision has to be reached in the case, the technological factor has to be addressed in some way, and it is here that the frame (construed by linguistic scientists as the cognitive structure established in order to facilitate comprehension) becomes a judicial frame and an argumentative technique that can be used in order to persuade through metaphors, or that application by analogy results in a shift from the familiar matrix to the new technological context.

It would appear to be necessary to draw a distinction here between a frame of resistance to technology on the one side and a frame of openness to the technological developments on the other. These value frames can be encapsulated in the inclination either to recognise or to reject the technological development in question as being built on the past.

In any case, whatever frame is chosen (that is, whether it is considered that there is continuity or discontinuity with the pre-existing technological framework), the operation will never be neutral, as it is conditioned by another important alternative which is often played down within the discussions of how the courts respond to technological change. This is the possibility that returning to the juxtaposition between the Hartian external and internal points of view, although in the more incisive understanding of MacCormick - the court may adopt either a perspective that is internal to the new technology or one that is external to it. A juxtaposition of this type between the external and internal points of view vis-à-vis technological developments was already apparent, avant la lettre in terms of the birth of the internet, in the Olmstead judgment $^{33}$ of the US Supreme Court, and in particular in the dissenting opinion of Justice Brandeis. According to the majority opinion in this case, the use of telephone conversations intercepted by federal agents, without having previously obtained a court order, as evidence in a trial did not violate the

32 Denver Area Educational Telecommunications Consortium, Inc. v FCC, 518 U.S. 727 (1996).

33 Olmstead v United States, 277 U.S. 438 (1928). 
Fourth Amendment as 'listening to a private telephone conversation did not require a physical search or entry into a person's private space'. By contrast, the judicial frame that permeated the dissenting opinion of Brandeis was diametrically opposed in nature and insisted on the recognition of technological discontinuity between the new technology (at that time) and the status quo; it thus leaned towards a teleological interpretation of search and seizure based on the Fourth Amendment. ${ }^{34}$

One might ask why such different frames were drawn upon by judges sitting at the same time in the same court. The difference may be accounted for precisely by distinguishing between the internal perspective of somebody involved in the game and the external perspective of the outsider. Ultimately, while the majority in the Court in Olmstead adopted an external perspective also in spatial terms - with regard to the person whose telephone conversation was tapped, Brandeis on the other hand, as an internal player (and not as an outsider), adopted his own judicial frame by considering the (at the time) new technology from a perspective that was internal to it, looking at the telephone network as a privileged means for creating a 'virtual closet, in which secrets', in the words of Brandeis, 'can be whispered'. On the basis of this value frame, which is structurally different from that adopted by the majority, Brandeis did not have any difficulty in concluding that, while it was not physical, there was nonetheless an intrusion - if not into private property, nonetheless into the private sphere of the persons whose conversation was tapped, thereby violating the Fourth Amendment.

While the possible juxtaposition between the external perspective and the internal perspective vis-à-vis the identification of technological developments may certainly have been apparent prior to the advent of the internet, it has been with the explosion of the Web that this juxtaposition has found its most fertile terrain, in which the dialectic between openness and resistance to such changes plays itself out. This cannot come as a surprise. It is in fact no coincidence that the internet is the only medium equipped with its own constitutive spatial metaphor: cyberspace. This is because, in contrast to other technologies, the context, or the frame of reference, is so constitutive and self-sufficient in nature as to be able to compete with physical reality, to the extent that it forces any court required to apply the law in relation to the internet to choose which perspective will characterise its judicial frame.

34 The Fourth Amendment of the US Constitution states: 'The right of the people to be secure in their persons, houses, papers, and effects, against unreasonable searches and seizures, shall not be violated, and no Warrants shall issue, but upon probable cause, supported by Oath or affirmation, and particularly describing the place to be searched, and the persons or things to be seized.' 
Considering the two passages cited at the outset, whereas the preference for the 'figurative meaning' over the technical meaning of the press expressed by the Joint Divisions of the Court of Cassation is indicative of an internal perspective that considers the intangible reality as a locus for the reconsideration of certain traditional categories or institutes, the ironic and provocative reference to the 'law of horses' by Easterbrook denotes an external perspective vis-à-vis the object of inquiry. This is a perspective that takes the analogue realm as a point of reference for the application of certain rules, with the digital dimension having the status of a mere accessory to which it is possible, and even advisable, to transfer sic et simpliciter traditional legal categories.

\section{FINAL REMARKS. METAPHORS IN DIGITAL LAW MATTER SHOULD BE HANDLED CAREFULLY: A FAKE NEWS CASE STUDY}

'The Internet is a new free marketplace of ideas.' This is the preferred metaphor $^{35}$ for those involved in the scholarly and public debate who support the thesis according to which the fake news issue should not be addressed (and faced) by public powers (and public law). The main idea behind such a thesis is that if in the world of atoms, as Justice Holmes wrote in 1919, 'the best test of truth is the power of the thought to get itself accepted in the competition of the market', ${ }^{36}$ this is even more true in the world of the internet, because the internet is amplifying the free exchange and competition of ideas and opinions. Consequently, according to the marketplace of ideas paradigm, if it is true that 'under the First Amendment there is no such thing as a false idea', ${ }^{37}$ in the material world this is even more true, thanks to the amplified opportunity to express thoughts and ideas in the digital world. In other words, public powers should not have any role in relation to the ever growing phenomenon of fake news on the internet, because Web users are (optimistically) supposed to have all the tools to select the most convincing ideas and the (most) true news, neglecting the unconvincing and fake news. In this sense there is complete trust in the self-correction capacity of the market of information.

Is there an alternative reading of the possible relationship between public powers, regulation and truth on the internet? Or should public law abdicate any role in the matter? In order to try to answer these questions, it is necessary to take a step back and ask: what is hidden under the label of fake news? A first 
tentative answer could include in the definition of fake news all information or news which shares a certain degree of falsehood. It could be a piece of information that is totally invented or information that is only partially false.

Obviously, as the right to be forgotten saga and many other issues are experiencing a second wave of consideration in the digital age, it is worth noting that the age of the fake news debate does not correspond to the age of the internet itself. It is evident that the global nature of the 'new' technology - the fact that virtually every internet user is able to become an editor and spread and share even false information, and the corresponding greater potential impact of falsehood on the internet - that exponentially amplifies the need and the urgency to verify the sources of information in the post-truth digital era. The real challenge is in how this verification process should be performed.

According to the champions of the free market of ideas metaphor, since, by definition, scarcity of resources is an analogical limit and not a digital one, and consequently there is no need to protect pluralism of information on the internet, legal rules (and especially public law rules) should take a step back in the name of the alleged self-corrective capacity of the information market. Just as the economic market knows no test of product validity but allows demand to drive supply, relying on the market to distinguish between viable and shoddy products, the best solution to address the fake news phenomenon in the information market is to secure the widest possible dissemination of every news item, even including those from contradictory and unreliable sources.

This proposal is not convincing, in my opinion, for at least three reasons. First, if it is true that the problem of scarcity of technical resources is not affecting the internet, attention and time available continue to be scarce 'products'. In fact, while the amount of information available is growing, the 24 hours per day of available time cannot be increased. Against this background, in this age of information overload, the temptation for the user will be to search for news, information and ideas which enhance their previous thoughts and preferences, adding to the group polarisation process well described by Cass Sunstein. ${ }^{38}$ In other words, in the world of bits, much more than in the world of atoms, deliberation tends to move groups, and the individuals who compose those groups, towards a more extreme point in the direction indicated by their own pre-determined judgments. The result seems to be that, in a quite paradoxical way, on the internet, despite (or perhaps better, exactly because of) the unlimited amount of information, there is a less pluralistic exchange of different opinions than is found in the traditional media, where there is still a scarcity-of-sources issue.

38 C Sunstein, Republic.com (Princeton University Press 2001). 
Second, it is reasonable to question whether the marketplace of ideas metaphor is appropriate for the scope of application (and limits) of the protection of free speech according to the European constitutionalism paradigm. First of all, in Europe the protection of freedom of expression is more limited than is the case for the US counterpart. It is enough to compare, in this respect, the wording of the US Constitution's First Amendment and Article 10 of the European Convention of Human Rights. Here it is not just a question of the different degree of the scope of application, but also a question of different focus. While the First Amendment mainly focuses on the active dimension related to the right to express his/her thoughts freely, Article 10 of the European Convention (and also Article 11 of the Charter of Fundamental Rights of the European Union) emphasises the passive dimension related to the right to be informed pluralistically. In this respect, it would be possible to argue that fake news is not constitutionally covered by the European vision of free speech, or at least would not be accepted by European courts. The US Supreme Court's opinion, in contrast, is the following: 'Under the First Amendment there is no such thing as a false idea. However pernicious an opinion may seem, we depend for its correction not on the conscience of judges and juries but on the competition of other ideas. ${ }^{39}$

Third, metaphorical language fits very well with legal reasoning, ${ }^{40}$ but it should be handled properly (and with care). A metaphor implies knowledge transfer across domains (from the Greek meta pherein, to 'carry over'). This means that we have two relevant constitutive domains: the source domain and the target domain. The free market of ideas metaphor carries over a systematic set of ideas that supersede the limitations of the older free speech model from the source domain of economic activity to the target domain of speech. In order to understand this fully, the features of the source 'market' domain should not be forgotten. Holmes made use of the metaphor in 1919 and the US Supreme Court applied it to the internet in 1997. Holmes wrote in a time of laissez-faire capitalism, in which the liberal State and competition in the market were at their best. If Holmes was sceptical about any external verification of the truth and removal of proven false news, the concept of a free market provided a meaningful alternative model for the notion that truth, like economic well-being, could be just the product of the completion of (true and false) ideas and information. Similarly, when the US Supreme Court borrowed the metaphor to call the internet the 'new marketplace of ideas', the internet

39 US Supreme Court, Gertz v Welch, 418 U.S. 323 (1974).

40 See from a US perspective, SL Winter, A Clearing in the Forest: Law, Life and Mind (University of Chicago Press 2001) and more than 30 years earlier, from a European perspective, A Giuliani, 'La nuova retoricae la logica del linguaggio normativo' (1970) XLVII, IV, 3-4, Rivista internazionale di Filosofia del diritto 374-90. 
market, in its genesis period, was absolutely free and not in any way affected by dominant positions or, even worse, by monopolies and oligopolies. In this context, the metaphor of the free marketplace of ideas and the proposed test for the truth (completion in the absence of any public power control) made perfect sense. By contrast, today, the same metaphor seems to be completely decontextualised: the economic market, the source domain from which the metaphor crossed over, is far from being 'free' but, as is well known in the DG Competition in Brussels and in every national Competition Authority, is characterised by huge market failures which require the ex post intervention of public powers. Against this background, if fake news is arguably the most significant and pervasive source failure in the marketplace of ideas, intervention by public powers could not be excluded, because the target domain of the metaphor, the digital market, has changed since the US Supreme Court defined the internet as a 'new free market place of ideas'. Far from being a free market, the digital market is characterised by economic concentrations and the strength of (a few) private powers.

Many questions emerge spontaneously at this stage. How should a constitutional State deal with new forms of private power in the algorithmic society? What are the new substantive and procedural rights which need to be recognised, and how can we ensure their enforcement? How can innovation (and the legal incentives for business to pursue innovation) be balanced with the need to ensure transparency and to protect those subject to the cybernetic complex? To what extent should new forms of public or private law tools be developed to address the challenges posed by the shift to the algorithmic society? Can transnational or comparative constitutional law (including the processes of borrowing and a migration of doctrine, procedure or theory) assist in addressing these challenges? Unfortunately, these questions will remain to some extent unanswered in this chapter. However, sometimes it is more important to raise the (hopefully) right question than to find the right answer. 